\title{
AN ORIENTATION TOWARD HELP-SEEKING FOR EMOTIONAL PROBLEMS
}

\author{
M. A. R. Tujhuis, L. Peters and M. Foets \\ Netherlands Institute of Primary Health Care (NIVEL), P.O. Box 1568, 3500 BN Utrecht, \\ The Netherlands
}

\begin{abstract}
In recent years, many researchers tried to explain the social selection in use of mental health care services. A modest role is attributed to the orientation toward help-seeking. This article studies this orientation. Our research-population consisted of 10,171 Dutch persons, aged 18 and older. Analysis showed that most people are prone to seek help for one or more emotional problems. People who are more prone to seek help are younger, have had more education and have a higher family income. They have more often acquaintances working in mental health care. People who are more prone to seek help do not see chance as the locus of control of health. These people are less dependent on their GP for common disorders and are more open about mental health matters. The results of discriminant analysis are not satisfactory, but when we try to distinguish the groups of people who are and who are not willing to seek help, we see that the best discriminating factor is their help-seeking attitude for common disorders. People who have high expectations from the GP for common disorders, clearly do have a preference to seek help for the emotional problems. The groups of people who are more willing to seek help from the GP compared to mental health professionals cannot be distinguished by these expectations. Here the level of education discriminates fairly well: people who are more prone to seek help from a GP have a lower educational level. Future research should be focussed on the testing of a theoretical model that explains the orientation toward help-seeking for emotional problems and selection in help-seeking with longitudinal data.
\end{abstract}

Key words -help-seeking orientation, emotional problems

\section{INTRODUCTION}

Many psychological problems are never brought to the attention of specific professional providers. Goldberg et al. [1] assume that most patients with psychological problems seek help at the primary care level (although in many cases not with well articulated psychological problems, but with somatic reasons for a visit), and that only a small proportion of them enters the specialized mental health care system. Within the group that reaches specialized mental health care, inequalities in age, socio-economic status and the like can be observed. Important factors in this respect are due to the health care system. For instance, in countries like the U.K. and the Netherlands, the specialized mental health care agencies are accessible, formally, only after referral by the general practitioner. The GP might have preferences in his referral policy for certain professionals and kinds of patients. A second important system factor might be the costs, attached to specialized mental health care, which may constitute serious barriers for some groups of patients.

Another possible explanation for differences between patients in help-seeking behaviour might be found on the part of the patient. Different orientations toward seeking specific professional help for psychological problems have proven to be important determinants of differences in actual help-seeking [2-12]. We think, therefore, that it is useful to explore the relationship between explanatory variables and this orientation. As Leaf et al. [13, p. 276] stated, "Knowledge of $(.$.$) correlates will allow for better$ targeting of future inventions to reduce barriers to the use of mental health services."

We return to our starting-point. The first filter in the well-known Goldberg and Huxley model reflects the help-seeking behaviour. Only a small proportion of the people in the community that feel some amount of stress (stage 1), presents this to the GP (stage 2). Kessler et al. [6] tried to explain this filtering process in terms of gender, amount of problems and orientation toward help-seeking ('propensity to seek care for psychological problems' as they call it). Here, we'll extend the model to other explanatory variables and concentrate on the relationship of individual characteristics and the orientation toward helpseeking (see Fig. 1). The variables related to an orientation toward help-seeking will be grouped into three categories: (1) personality characteristics. (2) demographic characteristics and (3) network characteristics.

Personality characteristics. One of the correlates with help-seeking attitudes is locus of control [14]. Respondents with an external locus of control showed a negative attitude toward help-seeking. A second characteristic of the personality that correlates significantly with a help-seeking orientation is authoritarianism. Highly authoritarian students and female respondents $[14,15]$ tend to express negative orientations. Fischer et al. [14] suggested that the ability to disclose oneself to another could be related to a help-seeking orientation. Subsequently they construct their scale for help-seeking orientation, which included several items about interpersonal openness. We feel (as they do $[14$, p. 88]) that this is not a dimension of 


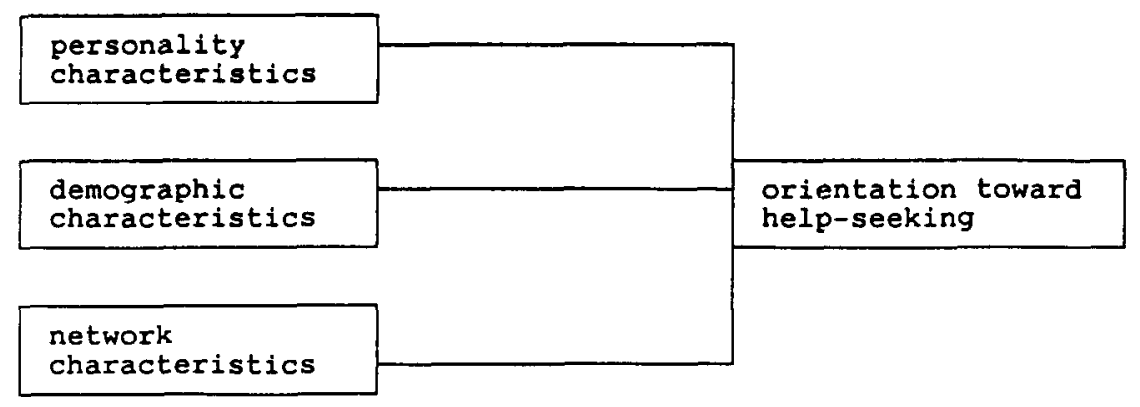

Fig. 1. Model posited to explain an orientation toward help-seeking.

help-seeking orientation, but merely one of the correlating personality characteristics. In the Fischer study, other personality characteristics showed significant correlations for men but not for women. This was the case for social desirability and trust in professionals and institutions for mental health.

Demographic characteristics. Gender, age, socioprofessional level, education and income are shown to affect a help-seeking orientation [6, 13, 15-17]. The findings for age are somewhat contradictory but female respondents with a higher education, socioprofessional level and income have a more positive help-seeking orientation.

Network characteristics. As Barbot [15] pointed out, women who knew somebody who had had psychotherapy held more favourable orientations. People who had prior contact with psychotherapists were also more positively oriented toward helpseeking for emotional problems $[17,18]$. Other characteristics of the network (like number of friends, meeting frequency) have not been included in the analysis for help-seeking orientation. However, these characteristics do have an influence on the use of mental health services [19]. Respondents with more friends and higher meeting frequency were less likely to use mental health services. Sherbourne [19] states that "The more social resources available to a person, the less likely that person is to use mental health services." It would be useful to examine whether these characteristics affect the help-seeking orientation.

\section{RESEARCH QUESTION}

As stated earlier, we will explore the model set up by Kessler et al. [6]. We have restricted ourselves to the relationship between individual characteristics and the oricntation toward help-sceking. Looking at earlier studies in this respect $[6,13-15,17,20]$, we see that only some variables are used to explain an orientation toward help-seeking. In this article we'll try to study most of the variables that are expected to be related to this orientation. The primary goal, therefore, is to examine the relationships between relevant personality characteristics, demographic and network characteristics and an orientation toward help-seeking.

This goal can be translated in two questions, relevant for this article. These are: (1) Is it possible to distinguish the people who are willing to seek help for emotional problems from those who are not, on the ground of certain individual characteristics? and (2) When we take a closer look at the people who are willing to seek help: Is it possible to distinguish the people who are willing to seek help from the GP from those who are willing to seek help from mental health care professionals (MHP) using individual characteristics?

Based on the earlier studies and on the available data, the following individual characteristics are selected. The personality characteristics chosen for analysis are locus of control, expectations from GP with respect to common disorders, and openness about mental health matters. We assume that people with an internal locus of control and who are open about mental health matters will be more oriented toward help-seeking. People who do expect a lot from the GP for common disorders are supposed to be highly dependent on the GP and will also be oriented toward help-seeking.

The demographic characteristics included in the analyses are gender, age, education, income and marital status. We assume that female, younger persons with a higher education and higher income will be more prone to seek help. Marital status has not been studied before in relationship with a helpseeking orientation. Research on social selectivity in seeking help for psychological problems [3] showed that unmarried people are more likely to apply for help at a counseling centre. In accordance with this finding, we assume that single persons will be more prone to seek help.

We have chosen three network characteristics, i.e. the number of close friends, whether or not people have acquaintances working in mental health care, and whether or not people have had prior contacts with mental health care professionals. As people with a lot of friends receive enough social support, we assume that people with more friends will not be oriented toward help-seeking. People with acquaintances working in mental health care will be more oriented toward help-seeking. People with prior contacts with mental health care professionals are assumed to be more willing to seek help for emotional problems.

As we do not control our analysis for number of problems or morbidity, we cannot say anything about the effect of the health-status of respondents on their orientation or vice versa. We'll return to this point in our discussion.

\section{METHOD}

Data were collected as part of the National Study of Morbidity and Interventions in General Practice in 
Table 1. Demographic characteristics of the sample $(N=10,171)$

\begin{tabular}{|c|c|c|c|c|c|}
\hline & $N$ & $\%$ & & $N$ & $\%$ \\
\hline \multirow{4}{*}{$\begin{array}{l}\text { Gender: } \\
\text { Male } \\
\text { Female }\end{array}$} & \multicolumn{5}{|c|}{ Marital status: } \\
\hline & 4969 & 48.9 & Not married & 2316 & 22.8 \\
\hline & 5202 & 51.1 & Married & 6824 & 67.1 \\
\hline & & & Widowed & 634 & 6.2 \\
\hline Education: & & & Divorced & 397 & 3.9 \\
\hline Highest & 1082 & 11.1 & Age: & & \\
\hline High & 1958 & 20.1 & $18-24$ & 1451 & 14.3 \\
\hline Low & 4054 & 41.5 & $25-44$ & 4556 & 44.8 \\
\hline Lowest & 2668 & 27.3 & $45-64$ & 2751 & 27.0 \\
\hline$(m v=409)$ & & & $65+$ & 1413 & 13.9 \\
\hline
\end{tabular}

the Netherlands [21]. In 1987, interviews were conducted among a random sample of 100 persons per general practitioner who took part in the study. The participating GPs form a random, nonproportional stratified sample of GPs in the Netherlands $(N=161)$. The interview consisted of 6 components, i.e. indicators of morbidity, health behaviour and use of health services, demographic variables, indicators of health-endangering habits, attitudes and beliefs, network characteristics and social support, and life events. The response rate for the interviews was $76.7 \%(N=13,067)$. We selected all respondents aged 18 and over for analysis $(N=10,171)$.

\section{Sample characteristics}

The demographic characteristics of the sample are presented in Table 1. As indicated by the table women comprise somewhat over half of the sample, about one-third of the respondents have had only lowest education, over $40 \%$ is middle-aged (between 25 and 44) and two-thirds of the respondents are married. Differences between the Dutch population and the population under study, concerning gender and age, are very small according to Foets et al. [22].

\section{The orientation toward help-seeking}

The questionnaires the respondents filled in during the interview, included a list about helpseeking orientation. This list combines 5 emotional problems with the orientation toward help-seeking. The respondents indicated to which (if any) of the professionals people should go for each of the problems. Possible answers were: general practitioner, social work, mental health services, and seeking no help at all. The answers of respondents are given in Table 2.
Because we want to distinguish the groups of people who are and who are not prone to seek help, we conducted Guttman scale statistics. For the purpose of Guttman scale analysis, the answers are recoded to $1=$ will seek help, and $0=$ will not seek help for each problem in the list (Table 3). The fifth item ('Someone is afraid of using an elevator. Who could he/she turn to?') scored badly; the $H_{i}$ coefficient [23] for this item was 0.16 . We left this item out. Loevingers' $H_{i j}$ between items varied from 0.51 to 0.68 . $H_{i} \mathrm{~s}$, Loevingers' $H_{i j} \mathrm{~s}$ and $H$ are high enough to draw the conclusion that we are dealing with a (Guttman) scale.

We determined scores for all respondents on this scale. To do so, we totalled the responses per respondent for each category. If, for example, a person answered that people should go to a GP for each of the problems in the list, he or she scores 4 times on 'help-seeking'. We assume that this score reflects what the respondents think they should do themselves.

As indicated by Table 4, nearly all respondents would turn to a professional for at least the first problem in the list (depression). Nearly $70 \%$ of all respondents would even turn to a professional for problems with raising a 9-year-old boy.

\section{Individual characteristics}

The demographic variables in this study are gender, age, marital status, household income and education. Education indicates the completed level of education.

Network characteristics of the respondents are the number of close friends, whether or not the respondents have acquaintances working in mental health care, and whether or not the respondents have had prior contacts with mental health care professionals.

The three personality characteristics chosen for this study are locus of control, expectations from GP for common disorders and openness about mental health matters. The locus of control scale we used [24] is a translated version of the Wallston [25] scale for health locus of control. This scale measures to what extent the respondent thinks his illness or health is determined by himself, the GP or by chance (Cronbach's alpha $0.76,0.80$ and 0.71 respectively).

Van de Lisdonk [26] developed a scale for 'expectations from GP for common disorders', named 'Nijmeegse Verwachtingen Lijst'. It is a list of common disorders which do not require medical

Table 2. Preference for professionals per emotional problem, in percentages

\begin{tabular}{|c|c|c|c|c|c|c|}
\hline \multirow[b]{2}{*}{ Item } & & \multicolumn{4}{|c|}{ Preference } & \multirow[b]{2}{*}{$N$} \\
\hline & & Nobody & $\begin{array}{l}\text { The } \\
\text { GP }\end{array}$ & $\begin{array}{l}\text { Social } \\
\text { work }\end{array}$ & $\begin{array}{l}\text { Mental } \\
\text { health } \\
\text { care }\end{array}$ & \\
\hline 1. & $\begin{array}{l}\text { Someone is having great difficulties } \\
\text { raising a 9-ycar-old boy. Who could give } \\
\text { him/her some advice about this? }\end{array}$ & 13.7 & 40.4 & 24.6 & 21.3 & 10.030 \\
\hline 2 & $\begin{array}{l}\text { Serious problems have arisen in a } 3- \\
\text { year-old marriage. Who would be the } \\
\text { best person for this couple to turn to? }\end{array}$ & 16.3 & 27.6 & 36.1 & 20.0 & 10,006 \\
\hline 3. & $\begin{array}{l}\text { Someone is feeling very lonely. Who } \\
\text { could he/she turn to? }\end{array}$ & 17.9 & 27.1 & 36.8 & 18.3 & 9991 \\
\hline 4. & $\begin{array}{l}\text { Someone has been depressed for } \\
\text { months. Who could he/she turn to? }\end{array}$ & 5.4 & 61.9 & 6.5 & 26.1 & 10,019 \\
\hline 5. & $\begin{array}{l}\text { Someone is afraid of using an elevator. } \\
\text { Who could he/she turn to? }\end{array}$ & 26.5 & 33.1 & 3.0 & 37.3 & 9994 \\
\hline
\end{tabular}


Table 3. Guttman scale statistics for help-seeking orientation

\begin{tabular}{|c|c|c|}
\hline Item & & $\begin{array}{c}H_{t} \\
\text { coefficient }\end{array}$ \\
\hline (4) & $\begin{array}{l}\text { Someone has been depressed for months. } \\
\text { Who could he/she turn to? }\end{array}$ & 0.64 \\
\hline (2) & $\begin{array}{l}\text { Serious problems have arisen in a } 3 \text {-year-old } \\
\text { marriage. Who would be the best person for } \\
\text { this couple to turn to? }\end{array}$ & 0.39 \\
\hline (3) & $\begin{array}{l}\text { Someone is feeling very lonely. Who could } \\
\text { he/she turn to? }\end{array}$ & 0.37 \\
\hline (1) & $\begin{array}{l}\text { Someone is having great difficulties raising a } \\
9 \text {-year-old boy. Who could give him/her } \\
\text { some advice about this? }\end{array}$ & 0.34 \\
\hline$H$ & & 0.41 \\
\hline
\end{tabular}

attention. The respondents are asked whether or not they would visit a GP for these disorders. The items in our questionnaire are a selection of 12 (out of 23 in Van de Lisdonk's study), all loading on one factor, resembling the dimensions of visiting the doctor for diagnostic or therapeutic reasons or to recover more quickly (Cronbach's alpha 0.91).

Respondents were asked to answer three questions about openness toward mental health care matters; whether people should hide the fact that they are in treatment for mental health problems, whether people should talk about existing problems (reversecoded), and whether people should take medicines to solve the problems. These items were combined in one measure for openness by totalling negative responses (Cronbach's alpha 0.80 ).

\section{RESLLTS}

Table 5 presents the mean score of respondents scoring extreme (the score of 0 or 1 compared to 3 or 4) on the orientation toward help-seeking per explanatory variable. The table also shows the significance of calculated $t$-test statistics.

It can be seen that there are significant differences between the groups of peope who are and who are not prone to seek help for personal problems. Of course, we must keep in mind that we are dealing with a very large sample here. Therefore, we only consider differences greater than $10 \%$ of importance. For our results this approximates the statistical significance with $P \leqslant 0.001$.

Most findings for respondents tending not to seek help at all for the problems in the list are in concordance with our expectations. This group is usually older, widowed and they more often have a lower level of education and income. They have less often acquaintances working in mental health care and have less often had prior contacts with mental health care professionals. The results for the number of

Table 4. Willingness to seek help for emotional problems, in percentages

\begin{tabular}{lc}
\multicolumn{2}{c}{$(N=9880)$} \\
\hline Score & Help-seeking \\
\hline $0 \times$ & 2.6 \\
$1 \times$ & 3.4 \\
$2 \times$ & 7.6 \\
$3 \times$ & 17.3 \\
$4 \times$ & 69.1 \\
Mean & 3.5 \\
SD & 1.0 \\
\hline
\end{tabular}

Table 5. Mean score per variable for people who are more willing to seek help $(N=8536)$ vs people who not $(N=593)$

\begin{tabular}{|c|c|c|}
\hline Variables & Yes & No \\
\hline $\begin{array}{l}\text { Gender }(1=\text { male, } 2=\text { female }) \\
\text { Age }(18-97)\end{array}$ & $\begin{array}{r}1.5 \\
42.2\end{array}$ & $\begin{array}{c}1.4^{*} \\
51.4^{* *}\end{array}$ \\
\hline $\begin{array}{l}\text { Marital status: } \\
\qquad \begin{array}{l}\text { I }=\text { not married } \\
\quad 1=\text { married } \\
1 \text { = widowed }\end{array} \\
\text { Education, I (low)-9 (high) } \\
\text { Income, } 1 \text { (low)-16 (high) }\end{array}$ & $\begin{array}{l}0.2 \\
0.7 \\
0.1 \\
2.9 \\
8.3\end{array}$ & $\begin{array}{l}0.1 * * \\
0.7 \\
0.2 * * \\
2.3 * * \\
6.9 * *\end{array}$ \\
\hline $\begin{array}{l}\text { Number of friends }(0-95) \\
\text { Acquaintances in mental } \\
\text { health care ( } 1=\text { yes }) \\
\text { Prior contact with MHP } \\
\quad(1=\text { yes })\end{array}$ & $\begin{array}{l}6.5 \\
0.2 \\
0.1\end{array}$ & $\begin{array}{l}6.4 \\
0.1 * * \\
0.0 * *\end{array}$ \\
\hline $\begin{array}{l}\text { Internal locus of control, } \\
\text { I (low)-31 (high) }\end{array}$ & 16.0 & 16.0 \\
\hline $\begin{array}{l}\text { GP as locus of control, } \\
\text { I (low)-3I (high) }\end{array}$ & 13.0 & 13.4 \\
\hline $\begin{array}{l}\text { Chance as locus of control, } \\
1 \text { (low)-31 (high) }\end{array}$ & 14.6 & $16.1^{* *}$ \\
\hline $\begin{array}{l}\text { Common disorder expectations } \\
\text { from GP, } 1 \text { (low)-49 (high) } \\
\text { Openness, } 1 \text { (low)-18 (high) }\end{array}$ & $\begin{array}{l}24.8 \\
13.7\end{array}$ & $\begin{array}{l}22.6 * * \\
12.8 * *\end{array}$ \\
\hline
\end{tabular}

Significance calculated from $t$-test statistics:

$* P \leqslant 0.05, * P \leqslant 0.001$.

friends, internal locus of control and GP as locus of control are not significant. Their score on chance as the locus of control is usually higher. This group is more often not open about mental health matters and does not expect much from GP for common disorders.

Next we will try to distinguish the two groups by discriminant analysis (Table 6).

The strongest discriminating factors here, are the extent to which people have expectations from the GP for common disorders and age. People who have higher expectations in this respect and people who are younger belong more often to the group of people who are willing to seek help. This group (respondents who are prone to seek help) can be well classified

Table 6. Weight of explanatory variables on a discriminant function with differences between extreme low and high scorers on the orientation to seek help $(N=9880)$, being maximalized

\begin{tabular}{lr}
\hline Variables & Weights \\
\hline Gender (1 = male) & 0.26 \\
Age (18-97) & -0.46 \\
Marital status: & 0.07 \\
I = not married & 0.07 \\
1 = married & -0.15 \\
l = widowed & 0.29 \\
Education, low (1)-high (9) & 0.17 \\
Income, low (1)-high (16) & -0.01 \\
Friends (0-95) & 0.12 \\
Acquaintances working in mental health care (1 = yes) & 0.10 \\
Prior contact with MHP (1 = yes) & -0.06 \\
Internal locus of control, low (1)-high (31) & -0.02 \\
GP as locus of control. low (1)-high (31) & -0.38 \\
Chance as locus of control, low (1)-high (31) & 0.75 \\
Expectations from GP for common disorders, low (1)-high & \\
$\quad$ (49) & 0.23 \\
Openness, low (1)-high (18) & 0.04 \\
Eigenvalue & 0.96 \\
Wilks' lambda & \\
\% Group members predicted in the right group: & 1.9 \\
Low score: respondents not prone to seek help & 99.9 \\
High score: respondents prone to seek help & 95.7 \\
All respondents & \\
\hline
\end{tabular}


Table 7. Guttman scale statistics for help-seeking orientation towards the GP or towards mental health care professionals $(N=9468)$

\begin{tabular}{llc}
\hline Item & \multicolumn{1}{c}{$\begin{array}{c}\boldsymbol{H}_{i} \\
\text { coefficient }\end{array}$} \\
\hline (4) & $\begin{array}{l}\text { Someone has been depressed for months. } \\
\text { Who could he/she turn to? }\end{array}$ & 0.57 \\
(2) $\quad \begin{array}{l}\text { Serious problems have arisen in a 3-year-old } \\
\text { marriage. Who would be the best person for }\end{array}$ & 0.44 \\
& $\begin{array}{l}\text { this couple to turn to? } \\
\text { (3) Someone is feeling very lonely. Who could } \\
\text { he/she turn to? }\end{array}$ & 0.43 \\
(1) Someone is having great difficulties raising a & 0.36 \\
9-year-old boy. Who could give him/her & \\
Some advice about this? & 0.43 \\
\hline
\end{tabular}

according to the statistics, but the characteristics of people who are not prone to seek help cannot be distinguished well.

Finding that the differences between the groups of people who are and people who are not prone to seek help for personal problems are not strong, one wonders what differences could exist between people who are prone to seek help for personal problems at the GP's office in contradiction with mental health care professionals. To answer this question we selected all respondents who are prone to seek help for at least one of the problems mentioned. Since we are dealing with a Guttman scale this means that we selected all persons who would seek help for being depressed $(N=9468)$. Recoding the answers of four items to (0) seeking help at the GP's office, and (1) seeking help from mental health professionals (social work plus mental health care), we see that here also a (Guttman) scale exists (Table 7).

Loevingers' $H_{i j}$ between items ranges from 0.53 to 0.71 . $H_{i}$ s, Loevingers' $H_{i j}$ s and $H$ are high enough to draw the conclusion that we are dealing with a (Guttman) scale again. Scores for each respondent are shown in Table 8. A score of 3 means that respondents are prone to seek help for difficulties raising a 9-year-old boy at the GP's office and, given the Guttman scale, are prone to seek help at the office of a mental health care provider for the three other problems in our list. Similarly, a score of 4 means that respondents are not prone to seek help from the GP for these problems, but are willing to go to mental health care professionals.

More people are willing to go to a mental health care professional $(22.6 \%)$ for all four personal problems mentioned than there are people willing to go to

\begin{tabular}{|c|c|}
\hline & \\
\hline Score & MHP \\
\hline $\begin{array}{l}0 \times \\
1 \times \\
2 x \\
3 \times \\
4 x\end{array}$ & $\begin{array}{l}17.9 \\
12.8 \\
20.3 \\
26.4 \\
22.6\end{array}$ \\
\hline $\begin{array}{l}\text { Mean } \\
\text { SD }\end{array}$ & $\begin{array}{l}2.2 \\
1.4\end{array}$ \\
\hline
\end{tabular}

Table 9. Mean score per variable for people who are more willing to seek help from the GP $(N=2907)$ vs from mental health care professionals (MHP) $(N=4639)$

\begin{tabular}{|c|c|c|}
\hline Variables & GP & MHP \\
\hline $\begin{array}{l}\text { Gender }(1=\text { male, } 2=\text { female }) \\
\text { Age }(18-97) \\
\text { Marital status: }\end{array}$ & $\begin{array}{r}1.6 \\
45.4\end{array}$ & $\begin{array}{r}1.5^{* *} \\
40.7^{* *}\end{array}$ \\
\hline $\begin{array}{l}\quad 1=\text { not matried } \\
\quad 1=\text { married } \\
1=\text { widowed } \\
\text { Education, I (low)-9 (high) } \\
\text { Income, } 1 \text { (low)-16 (high) }\end{array}$ & $\begin{array}{l}0.2 \\
0.7 \\
0.1 \\
2.5 \\
7.7\end{array}$ & $\begin{array}{l}0.3^{* *} \\
0.6^{* *} \\
0.0^{* *} \\
3.1^{* *} \\
8.5^{* *}\end{array}$ \\
\hline $\begin{array}{l}\text { Number of friends }(0-95) \\
\text { Acquaintances in mental } \\
\text { health care }(1=\text { yes }) \\
\text { Prior contact with MHP } \\
\quad(1=\text { yes })\end{array}$ & 0.1 & $\begin{array}{l}6.4^{*} \\
0.2^{* *}\end{array}$ \\
\hline $\begin{array}{l}\text { Internal locus of control, } \\
1 \text { (low)-31 (high) } \\
\text { GP as locus of control, }\end{array}$ & 16.1 & 16.0 \\
\hline $\begin{array}{l}\text { Chance as locus of control, } \\
1 \text { (low) } 31 \text { (high) }\end{array}$ & 15.5 & $14.2^{* *}$ \\
\hline $\begin{array}{l}\text { Common disorder expectations } \\
\text { from GP, } 1 \text { (low) }-49 \text { (high) } \\
\text { Openness, I (low)-18 (high) }\end{array}$ & $\begin{array}{l}25.8 \\
13.3\end{array}$ & $\begin{array}{l}24.2^{* *} \\
13.9^{* *}\end{array}$ \\
\hline
\end{tabular}

Significance calculated from $t$-test statistics:

$* P \leqslant 0.05, * * P \leqslant 0.001$.

the GP (17.9\%). Table 9 shows differences between the groups of people with a preference for the GP vs mental health care professionals (the score of 0 or 1 compared to 3 or 4 ).

Nearly all individual characteristics differ between the two groups. People who have a greater tendency to seek help from mental health care professionals compared to people who have a greater tendency to seek help from a GP are more often male, younger and not married. These people have a higher educational level and a higher income than people who are prone to seek help from the GP. They also have more often acquaintances working in mental health care. Finally, these people see the GP or chance as their locus of control less often, they have lower expectancies from the GP for common disorders and are more open about mental health matters. In Table 10 we show the results of discriminant analysis, used to distinguish the two groups more pronounced.

As can be seen, education distinguishes the two groups at best. Still, the results of the analysis are not satisfactory at all. The percentage group members that can be classified in the group 1 and Wilks' lambda are not as high as they should be to make an accurate distinction between the two groups.

\section{DISCUSSION}

Some of the variables we used in our analyses (i.e. marital status, number of friends, whether or not the respondent has acquaintances working in mental health care, expectations the respondent had from the GP for common disorders, and openness) were not used before in the studies mentioned in the introduction, and can therefore not be compared to results of others. Making the possible comparisons between our results and those of others we see that we can confirm most of the findings. 
Table 10. Weight of explanatory variables on a discriminant function with differences between low scorers on seeking help from mental health care professionals $(N=2907)$ and high scorers on sceking help from mental health care professionals ( $N=4639$ ), being maximalized

\begin{tabular}{lr}
\hline Variables & Weights \\
\hline Gender (1=male) & -0.12 \\
Age (18-97) & -0.29 \\
Marital status: & 0.32 \\
$1=$ not married & -0.10 \\
$1=$ married & -0.07 \\
I = widowed & 0.52 \\
Education, low (1)-high (9) & 0.15 \\
Income. low (1)-high (16) & -0.13 \\
Friends (0-95) & 0.00 \\
Acquaintances working in mental health care (1 & 0.07 \\
Prior contact with MHP (1 = yes) & -0.03 \\
Internal locus of control. low (1)-high (31) & -0.02 \\
GP as locus of control. low (1)-high (31) & -0.16 \\
Chance as locus of control, low (1)-high (31) & 0.06 \\
Expectations from GP for common disorders, low (1)-high & \\
$\quad$ (49) & 0.10 \\
Openness, low (1)-high (18) & 0.05 \\
Eigenvalue & 0.96 \\
Wilks lambda & \\
\% Group members predicted in the right group: & \\
Low score: & \\
respondents prone to seek help from the GP & 6.6 \\
High score: & \\
respondents prone to seek help from mental health care & 96.7 \\
professionals & \\
All respondents & 67.6 \\
\hline
\end{tabular}

Several authors $[13,14,16,17]$ suggested that women held more positive attitudes toward helpseeking than men. Others $[27,28]$ did not find a difference in help-seeking orientation between the sexes. The samples of most of these studies consist of students, as they do in the case of Dadfar [27] and Zeldow [28] too. In our case, a representative sample, we found a very small difference in orientation toward help-seeking between the sexes, possibly due to our large sample. Future research in this respect is needed.

In our study, younger people were more willing to seek help than older people, which confirms the findings of Leaf et al. [13]. Several authors $[13,15,17,20]$ also indicated the positive relationship between education and income, and the orientation toward help-seeking we found. That people with prior contacts with mental health care appeared to be more willing to seek help in our study, was also found by the majority of authors on this subject $[14,15,17,18,27,29]$. As our measure of locus of control differs from the one used by Fischer $e t$ al. [14], we cannot compare our results completely. Nevertheless, in both studies 'externals' were less oriented toward help-seeking.

Unfortunately we have not found any publications about a help-seeking attitude towards specific professionals. Frank et al. [30] used a similar measure for help-seeking behaviour, but they did not include an orientation toward help-seeking in their analyses. Their main conclusion was that (mental) health plays an important role in the decision to seek care but has little effect on the type of provider chosen. As mentioned earlier, we did not control our analysis for health status.
The results of our discriminant analysis were not satisfactory. Other, more discriminating, individual characteristics have to be found (for instance 'threat to self-esteem', as suggested by Amato et al. [31] and by Nadler [32]). One way to start this research is by giving some more theoretical background for the analysis. The work of Kessler et al. [6], mentioned earlier, is one step in this direction. In this respect, we have to keep the ultimate goal in mind. This is, we want to explain why certain people do seek help for their emotional problems and others do not. One important variable, of course, is the amount of problems people have. In the case of one of our network variables for instance, there exists extensive literature about the effect of social support on this amount of problems. To explore the relationship of an orientation towards help-seeking. the amount of problems and the actual help-seeking, one should have longitudinal data. As several authors $[17,18,20,28]$ pointed out, people with prior contacts (whether positive or not) with mental health care have a more positive orientation toward help-seeking. We should keep in mind that older people have had more opportunities to use mental health services. So when we try to determine the effect of the orientation on actual help-seeking we should at least have longitudinal data. In the studies about selectivity in the use of mental health care mentioned earlier, there is not much attention for this causality problem. Some researchers had longitudinal data [12] at their disposal and did not have to worry about causality. Others $[7,17]$ have not determined the causal direction of the relationship between the orientation and the use of mental health care: "Those who are in treatment may use being in treatment as an indicator of a positive orientation" [7, p. 1334], but recognize the problem. We feel that this causality problem should be solved before going on with this subject.

\section{REFERENCES}

1. Goldberg D. P. and Huxley D. Mental Illness in the Community. The Pathway to Psychiatric Care. Tavistock, London, 1980.

2. Greenley J. R. Social factors, mental illness and psychiatric care: recent advances from a sociological perspective. Hosp. Commun. Psychiat. 35, 813, 1984.

3. Greenley J. R. and Mechanic D. Social selection in seeking help for psychological problems. J. Hith soc. Behav. 17, 249, 1976.

4. Greenley J. R., Mechanic D. and Cleary P. D. Seeking help for psychologic problems. A replication and extension. Med. Care 25, 1113, 1987.

5. Hosman C. M. H. Psychosociale problematiek en hulpzoeken. Een sociaal-epidemiologische studie ten behoete van de preventieve geestelijke gezondheidszorg. Dissertation Catholic University of Njmegen, Swets \& Zeitlinger, Lisse, 1983.

6. Kessler R. C., Reuter J. A. and Greenley J. R. Sex differences in the use of psychiatric outpatient facilities. Soc. Forces 58, 557, 1979. Gove W. and Swafford M. Sex differences in the propensity to seek psychiatric treatment: prevailing folk beliefs and misused log-linear analysis-Comment on Kessler et al. Soc. Forces 59, 1281, 1981. Kessler R. C. Reply to Gove and Swafford. Soc. Forces 59, 1291, [981. 
7. Leaf P. J.. Livingston B. M., Tischler G. L., Weissman M. M.. Holzer III C. E. and Myers J. K. Contact with health professionals from the treatment of psychiatric and emotional problems. Med. Care 23, $1322,1985$.

8. Leaf P. J., Livingston B. M. and Tischler G. L. The differential effect of attitudes on the use of mental health services. Soc. Psychiat. 21, 198, 1986.

9. Leaf P. J. and Livingston B. M. Gender differences in the use of mental health-related services: a reexamination. J. Hlth soc. Behav. 28, 171, 1987(a).

10. Mechanic D., Cleary P. D. and Greenley J. R. Distress syndromes, illness behavior, access to care and medical utilization in a defined population. Med. Care 20, 361, 1982.

11. Robbins J. M. Lay attribution of personal problems and psychological help-seeking. Soc. Psychiat. 16, 1, 1981.

12. Tessler R., Mechanic D. and Dimond M. The effect of psychological distress on physician utilization: a prospective study. J. Hlth soc. Behav. 17, 353, 1976.

13. Leaf P. J., Livingston B. M., Tischler G. L. and Holzer III C. E. The relationship between demographic factors and attitudes toward mental health services. J. Commun. Psychol. 15, 275, 1987(b).

14. Fischer E. H. and Turner J. LeB. Orientations to seeking professional help: development and research utility of an attitude scale. J. consult. clin. Psychol. 35, 79,1970

15. Barbot F. M. de. A cross-cultural study of attitudes toward seeking professional psychotherapeutic help. Dissert. Abstr. Int. 38, 1875, 1977.

16. Sanchez A. R. and Atkinson D. R. Mexican-American cultural commitment, preference for counselor ethnicity, and willingness to use counseling. $J$. Counsel. Psychol. 30, 215, 1983.

17. Surgenor L. J. Attitudes toward seeking professional psychological help. N. Z. J. Psychol. 14, 27, 1985.

18. Kligfeld $M$. Medical student attitude toward seeking professional psychological help. Dissert. Abstr. Int. 39, 4143A, 1979.

19. Sherbourne C. D. The role of social support and life stress events in use of mental health services. Soc. Sci. Med. 27, 1393, 1988.
20. Fischer E. H. and Cohen S. L. Demographic correlates of attitude toward seeking professional psychological help. J. consult. clin. Psychol. 39, 70, 1972.

21. Foets M., Velden J. van der and Zee J. van der. Morbidity and interventions in general practice. A crossnational suriey in the Netherlands. Study design. Netherlands Institute of Primary Health Care (NIVEL), Utrecht, 1986

22. Foets $M$. and Velden J. van der. Methoden tan onderzoek. Basisrapport van de Nationale Studie ran Ziekten en Verrichtingen in de Huisartspraktijk. NIVEL, Utrecht, 1990 (in press).

23. Swanborn P. G. Schaaltechnicken. Theorie en praktijk van acht eenvoudige procedures. Boom, Meppel, Amsterdam. 1982

24. Halfens R. J. G. Locus of control: de beheersingsorientatie in relatie tot ziekte - en gezondheidsgedrag. Dissertation State University of Masstricht, 1985.

25. Wallston K. A., Wallston B. S. and DeVellis $\mathbf{R}$. Development of the multidimensional health locus of control (MHLC) scales. Hith Educ. Monogr. 6, 160 , 1978.

26. Lisdonk E. H. van de. Ervaren en aangeboden morbiditeit in de huisartspraktijk. Een onderzoek met dagboeken. Dissertation Catholic University of Nijmegen, 1985

27. Dadfar S. and Friedlander M. L. Differential attitudes of international students toward seeking professional psychological help. J. Counsel. Psychol. 29, 335, 1982.

28. Zeldow P. B. and Greenberg R. P. Attitudes toward women and orientation to seeking professional psychological help. J. clin. Psychol. 35, 473, 1979.

29. Cash T. F., Kehr J. and Salzbach R. F. Help-seeking attitudes and perceptions of counselor behavior. J. Counsel. Psychol. 25, 264, 1978.

30. Frank R. G. and Kamlet M. S. Determining provider choice for the treatment of mental disorder: the role of health and mental health status. Hlth Sert. Res. 24, 83 . 1989.

31. Amato P. R. and Saunders J. The perceived dimensions of help-seeking episodes. Soc. Psychol. Q. 48, 130, 1985.

32. Nadler A. Determinants of help seeking behaviour: the effect of helpers similarity, task centrality and recipient's self esteem. Eur. J. Soc. Psychol. 17, 57, 1987. 